\title{
LA-UR-97= 3384
}

Approved for public release;

distribution is unlimited

Title:

\section{A Framework for Hierarchical, Object- Oriented Simulation Modeling of a Steel Manufacturing Enterprise}

Authors:

Submitted to:

A. D. Henriksen, TSA-7

E. L. Joyce, CIT/ET-PO

D. A. Korzekwa, MST-6

B. R. Lally, ESA-EPE

R. F. Hinde, ESA-EPE

R. P. Currier, ESA-EPE

K. L. Buescher, X-CM

V. Hanagandi, X-CM

C. Chandra, TSA-7

A. Redondo, T-12

S. Chitanvis, T-12

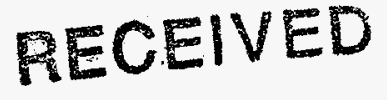

OCT 011997

OSTI

DOE Office of Scientific and Technical Information (OSTI)

\section{Los Alamos}

NATIONAL LABORATORY

Los Alamos National Laboratory, an affirmative action/equal opportunity employer, is operated by the University of Califomia for the U.S. Department of Energy under contract W-7405-ENG-36. By acceptance of this article, the publisher recognizes that the U.S. Government retains a nonexclusive, royaltyfree license to publish or reproduce the published form of this contribution, or to allow others to do so, for U.S. Government purposes. Los Alamos National Laboratory requests that the publister identify this article as work performed under the auspices of the U.S. Department of Energy. Los Alamos National Laboratory strongly supports academic treedom and a researcher's right to publish; as an institution, however, the Laboratory does not endorse the viewpoint of a publication or guarantee its technical correctness. 


\section{DISCLAMMER}

Portions of this document may be illegible in electronic image products. Images are produced from the best available original document. 


\section{DISCLAIMER}

This report was prepared as an account of work sponsored by an agency of the United States Government. Neither the United States Government nor any agency thereof, nor any of their employees, make any warranty, express or implied, or assumes any legal liability or responsibility for the accuracy, completeness, or usefulness of any information, apparatus, product, or process disclosed, or represents that its use would not infringe privately owned rights. Reference herein to any specific commercial product, process, or service by trade name, trademark, manufacturer, or otherwise does not necessarily constitute or imply its endorsement, recommendation, or favoring by the United States Government or any agency thereof. The views and opinions of authors expressed herein do not necessarily state or reflect those of the United States Government or any agency thereof. 


\title{
A Framework for Hierarchical, Object-Oriented Simulation Modeling of a Steel Manufacturing Enterprise
}

Anne D. Henriksen', Edward L. Joyce, David A. Korzekwa, Bryan R. Lally, Ralph F. Hinde, Robert P. Currier, Kevin L. Buescher, Vijaykumar Hanagandi, Charu Chandra, Antonio Redondo and Shirish Chitanvis

\begin{abstract}
This is the final report of a two-year, Laboratory Directed Research and Development (LDRD) project at the Los Alamos National Laboratory (LANL). The objective of the project is to combine detailed physical models of industrial processes with unit operations and business-level models. This would allow global and individual process control schemes to be implemented that would facilitate improved overall system performance. Intelligent decision support that employs expert system concepts (knowledge base and rules) could then also be incorporated. This project is innovative because it attempts to incorporate all levels of production-related activities from atoms to enterprise, and to integrate those activities into one comprehensive decision support tool. This project is an interdisciplinary effort requiring enterprise modeling and simulation model integration; process modeling and control; process control and optimization; chemical process modeling; and detailed molecular-level models. It represents the state of the art in enterprise modeling and simulation and incorporates cutting edge process modeling, process control, and system optimization techniques.
\end{abstract}

\section{Background and Research Objectives}

Many efforts are currently in place in the US to increase US industrial competitiveness in global markets. These efforts revolve around the idea that industries are systems, the totality of which make up an industrial enterprise. Improving industrial performance and competitiveness, therefore, is best served by a systems engineering approach. Los Alamos National Laboratory (LANL) expertise in systems modeling and analysis can assist in these efforts. Through computer simulation of both continuous- and discrete-event industry models, we can analyze complex interactions among unit operations that comprise an industrial "system". Optimal combinations of resources, financial capital, and environmental considerations can be evaluated and coupled with an integrated systems solution.

\footnotetext{
- Principal Investigator, E-mail: adh@lanl.gov
} 
Like private-sector enterprises, the Department of Energy (DOE) must also manage its operations in a competitive and efficient manner. The results of this project can be used to study and improve the effectiveness of DOE complex-wide facility interactions, in particular, those associated with managing the plutonium legacy and stockpile stewardship. Success would also be immediately applicable to the materials processing and manufacturing operations of DOE, because they require a high level of coordination in order to minimize waste.

The specific goals of this project were as follows:

- Develop an integrated, object-oriented system simulation model of the top three layers of the atoms-to-enterprise hierarchy (see attached figures)

- Develop process models of selected steel production unit operations and molecular-level models of selected steelmaking processes for eventual integration into the model of the top three layers

- Establish relationships with members of the steel industry

- Generate follow-on support from either DOE or industry.

\section{Importance to LANL's Science and Technology Base and National R\&D Needs}

The strategy to be developed is fully consistent with actively enhancing LANL's missions. Efforts at LANL in the areas of process engineering, materials science, computer simulation, and energy and environmental analyses are extensive and well established. This project adds to LANL's core competency in each of these areas, and it provides high visibility within US industry on a project with strong long-term benefits to the US economy.

The idea of integrated systems modeling for materials processing will be especially important to the weapons complex in the current environment where neither process emissions nor device testing are permitted. These ideas have been very favorably received 
by the people responsible for the Advanced Design and Production Technologies (ADaPT) and Accelerated Strategic Computing Initiative (ASCD) programs. The possibilities of implementing some or all of our simulation and control concepts as part of ADaPT/ASCI are very good.

Specific areas called out in the Laboratory strategic plan include support of the civilian sector as it relates to the energy subsector; specifically, efforts in conservation and renewable energy. This also is in line with two of DOE's major strategic areas: industrial competitiveness and energy efficiency. Another area of support is the industry subsector, which calls for dual-use technology transfer. Lastly, in the environmental subsector of the civilian sector, efforts call for expanding laboratory partnerships with industry in the environmental technologies as they relate to waste minimization.

\section{Scientific Approach and Accomplishments}

The goal of the project was to demonstrate an integrated simulation scheme for plant design, development, and optimal plant performance. This effort linked complex individual unit operation models into an integrated simulation of the manufacturing and business functions. A detailed flowsheet representing the hierarchical steel manufacturing enterprise is shown in Fig. 1 and a flowsheet outlining the hierarchical system simulation is shown in Fig. 2.

The major technical accomplishments of this project are:

- Developed hierarchical framework for integrating the functions of a steel manufacturing enterprise spanning atomic- to enterprise-level activities (see Fig. 1).

- Developed object-oriented system simulation of selected processes on the top two levels of the atoms-to-enterprise hierarchy integrated with all the elements on the third (manufacturing) level (see Fig. 2).

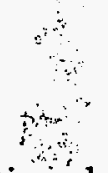

- Developed a blast-furnace mass-balance process model (at the unit operations level) for integration with the above system simulation . 
- Developed a basic oxygen process (BOP) carbon endpoint model (at the unit operations level) based on nonlinear model predictive control.

- Developed a BOP kinetics model (at the molecular level) for predicting carbon endpoint, which would be integrated with the nonlinear model predictive control model.

\section{Publication}

A. D. Henriksen, "A Framework for Hierarchical, Object-Oriented Simulation Modeling of a Steel Manufacturing Enterprise,"Proceedings of the 1996 Society for Computer

Simulation (SCS) Western Multiconference-Object-Oriented Simulation Conference, San Diego, January 14-17, 1996. 


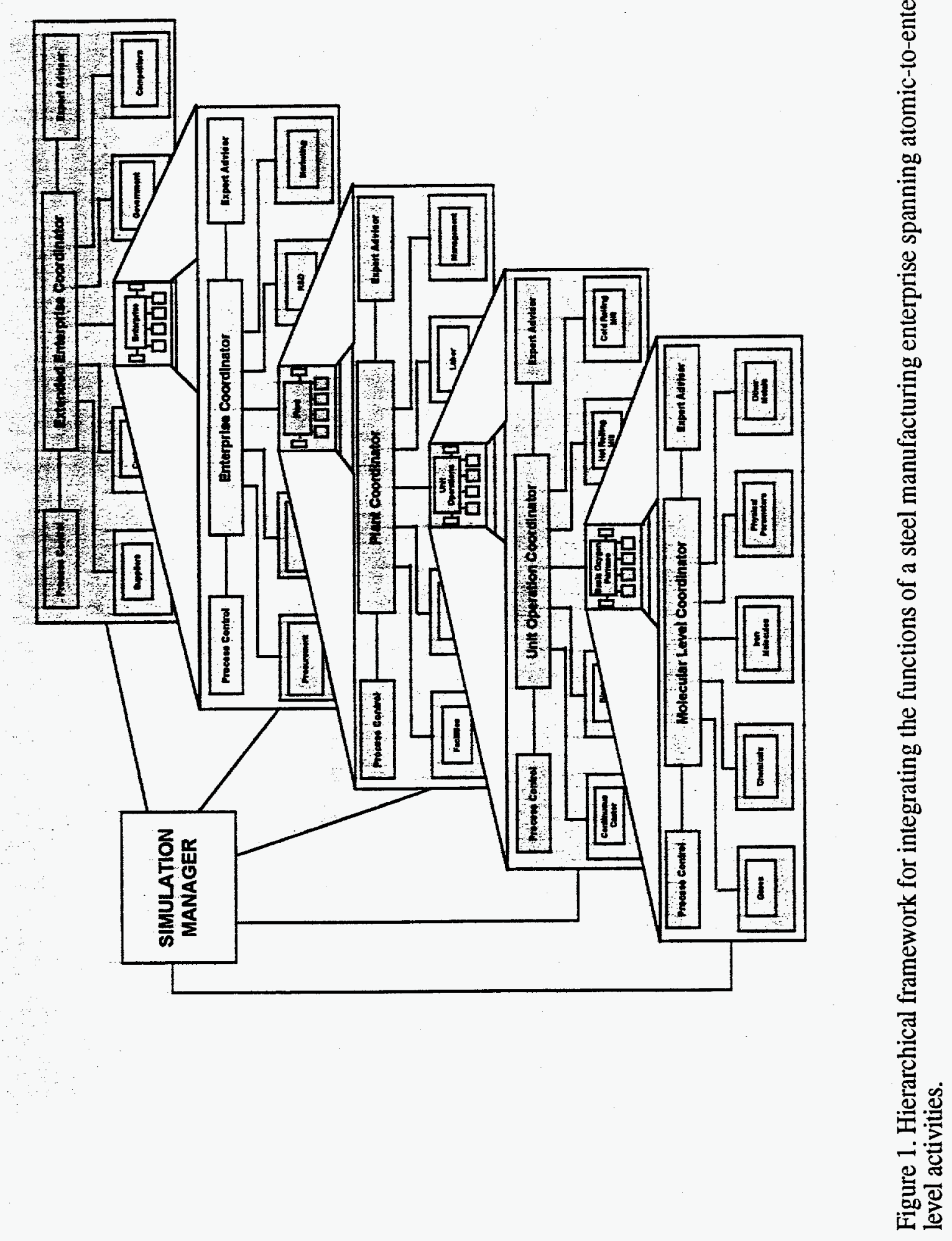



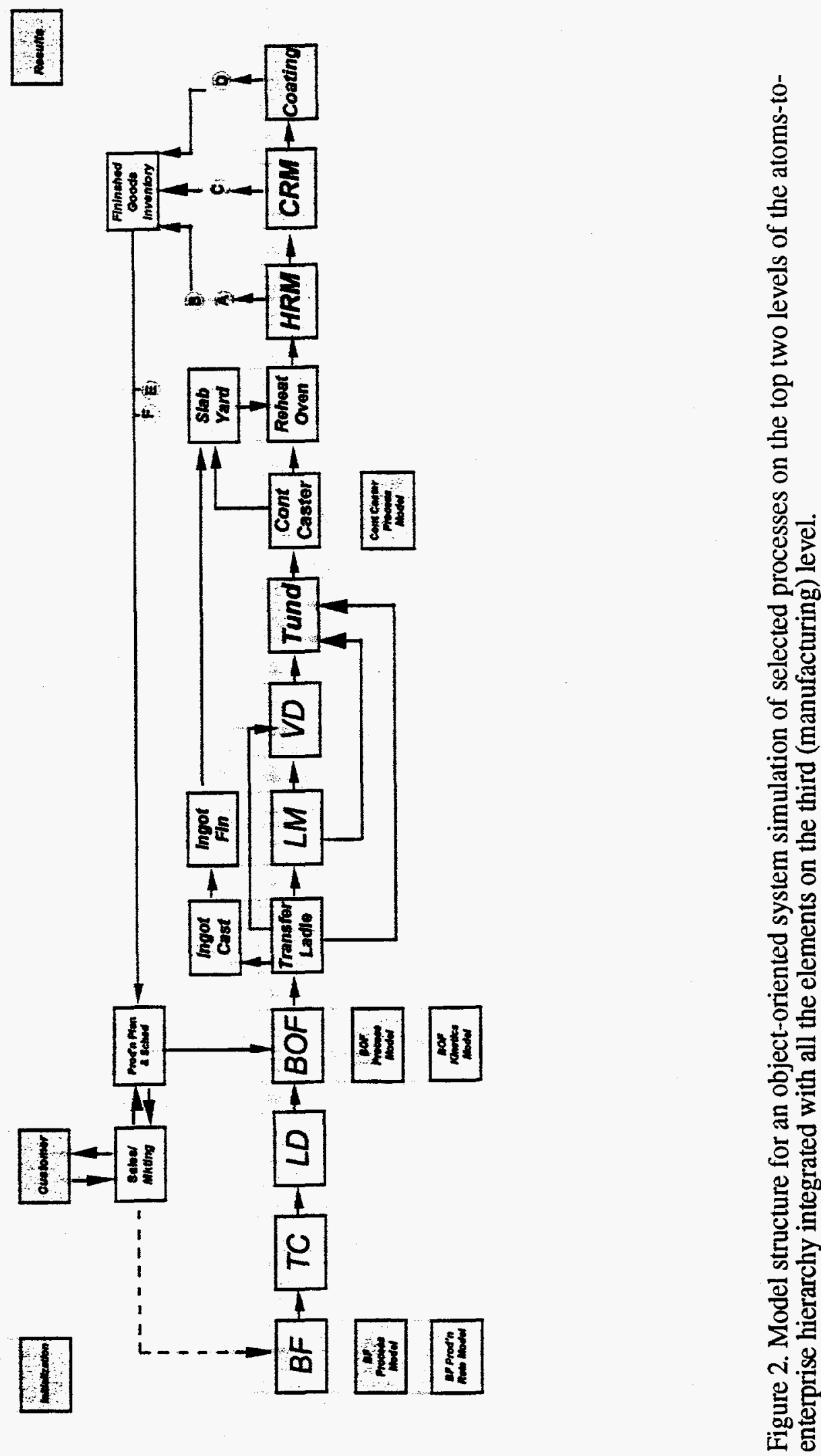